American Journal of Applied Sciences 7 (2): 185-190, 2010

ISSN 1546-9239

(C) 2010 Science Publications

\title{
Technical Efficiency of Chili Production
}

\author{
A.S.M. Anwarul Huq and Fatimah Mohamed Arshad \\ Institute of Agricultural and Food Policy Studies, University Putra Malaysia, \\ Putra Infoport, 43400 Serdang, Selangor Darul Ehsan, Malaysia
}

\begin{abstract}
Problem statement: Scarcity of resources has led to production economists to think about the reallocation of existing resources to produce a prescribed level of output with the minimum cost without changing the production technology. But there is a lack of information about the efficient use of inputs in chili production. Except for a few descriptive studies, econometric analysis has yet to be conducted to examine the production function for chili cultivation and its potential for future improvement in Bangladesh. Approach: In this study an effort was made to assess the level of technical efficiency required for chili production in the administrative district of Jamalpur and also analyzed the status of resource allocation for its production. The Cobb-Douglas stochastic production frontier model was used to analyze the data. Results: The study revealed that cultivation of chili is highly profitable. The net return against cultivating of chili was Tk $73,164 \mathrm{ha}^{-1}$ while the Benefit Cost Ratio (BCR) was 1.93. However, all the farmers were not very close to the maximum frontier outputs (efficiency levels varying from $11-96 \%$ and their mean efficiency was $77 \%$ ). Conclusion: On an average, $23 \%$ technical inefficiency appears which implies that the output per farm can be increased on an average by $23 \%$ through chili production using the prevailing technology and without incurring any additional production cost. Side by side advanced technology (high yielding variety, disease and pest management) could be adapted to increase production of this particular spice.
\end{abstract}

Key words: Technical efficiency, chili

\section{INTRODUCTION}

Chili pepper (English) whose botanical name is Capsicum annuum (chili peppers) and Capsicum frutescens (includes bird's eye chili) are widely used as a condiment and spice all over the world. Chili peppers are native to South and Central America. They were introduced in South Asia in the 1500 s and have come to dominate the world spice trade. India is now the largest producer of chilies in the world followed by China and Pakistan. World production of chilies during 2007-08 was estimated to be 20.98 lakh tones. The top-10 chili producing countries-India, China, Ethiopia, Myanmar, Mexico, Vietnam, Peru, Pakistan, Ghana and Bangladesh, accounted for more than $85 \%$ of the world production in 2007 . The lion's share is taken by India with $36 \%$ share in global production, followed by China $11 \%$, Bangladesh $8 \%$, Peru 8\% and Pakistan 6\% (Karvy, 2008). Chili pepper is thought to be the most popular spice with over $20 \%$ of the worlds' population using it in some form or the other.
Chili powder is a world renowned spice that is used in many cuisines and recipes of various cultures to add a tangy taste to them. Chilies were readily incorporated into the local South Asian cuisines perhaps because people were already familiar with pungent and spicy flavors. Mounds of red chili powder and yellow turmeric powder give splashes of vibrant color to every food market in Bangladesh today. The fruits are consumed fresh, dried or processed (in powdered or crushed form) as a spice. In South Asia it is grinded or chopped and added to spice mixtures and dishes where it adds a hot flavor.

Chili is one of the most important as well as cash crop in Jamalpur district and also in the whole of Bangladesh. Farmers cultivate it with their innovative ideas on variety, fertilizer dose and agronomic practices. Chilies are produced seasonally but consumed throughout the year. It is a much simpler crop to cultivate with duration of 3-4 months. It can survive on different soil types and several climatic conditions. But the best output of this crop is obtained when it is grown on deep, loamy, fertile soil with

Corresponding Author: A.S.M. Anwarul Huq, Institute of Agricultural and Food Policy Studies, University Putra Malaysia, Putra Infoport, 43400 Serdang, Selangor Darul Ehsan, Malaysia Tel: +6-03-89471076/+6 0149672483 Fax: +6-03-89471077 
appropriate moisture content. The soil is ploughed properly at the time of planting of the crop. Plants are propagated by seed, often in nursery beds and then transplanted into fields later. The pods are marketed both in green and red or natural form. Some chilies are dried and sun-drying is common in Bangladesh, which often takes place on mats in fields and by roadsides. These can be stored for months before selling or can be further processed into sauces or as grinded powder form.

Scarcity of resources has led to production economists to think about the reallocation of existing resources to have more output with given level of input combinations or to produce a prescribed level of output with the minimum cost without changing the production technology. But there is a lack of information about the efficient use of inputs in chili production. Similarly, the measurement of the productive efficiency in agricultural production is an important issue because it gives pertinent information for making sound management decision in resource allocation. Except for a few descriptive studies, econometric analysis has yet to be conducted to examine the production function for chili cultivation and its potential for future improvement. Considering the above facts, the present study was under taken, to determine the level of technical efficiency of the chili producing farmers and to analyze the status of resource allocation.

\section{MATERIALS AND METHODS}

Location and sample: Jamalpur district as an important chili growing area, which was selected purposively for the present study. Six villages were selected from Sadar Upazila of Jamalpur districts, where it is cultivated extensively. A total of 100 chili growers were selected. Simple random sampling technique was used to select the farmers. Data were collected by visiting each farm personally and by interviewing them with the help of a pre-tested interview schedule. The reference period for the survey was 2008-09.

Analytical Framework: The stochastic production frontier and technical inefficiency model: Following the standard assumption that farmers maximize expected profits (Zellner et al., 1966), a single equation stochastic frontier function for the cross-sectional data can be defined as:

$Y_{i}=f\left(X_{i} ; \beta\right) \exp \left(V_{i}-U_{i}\right)$
Where:

$Y_{i}=$ Production of the $i-t h$ sample $(i=1,2, \ldots \ldots, n)$

$\mathrm{X}_{\mathrm{i}}=\mathrm{A}(1 \times \mathrm{k})$ vector of functions of input quantities used by i-th farm

$\beta=\mathrm{A}(\mathrm{k} \times 1)$ vector parameters to be estimated

$\mathrm{V}_{\mathrm{i}} \mathrm{S}=$ Assumed to be independently and identically distributed $\mathrm{N}\left(0, \sigma \mathrm{v}^{2}\right)$ random errors, independent of the $U_{i} s$

$\mathrm{U}_{\mathrm{i}} \mathrm{S}=$ Non-negative random variables, associated with technical efficiency in production, which are assumed to be independently and identically distributed and truncated (at zero) of the normal distribution with zero mean

According to Battese and Colli (1995), the technical inefficiency effects, $U_{i}$ in Eq. 1 could be expressed as:

$\mathrm{U}_{\mathrm{i}}=\mathrm{Z}_{\mathrm{i}} \delta+\mathrm{W}_{\mathrm{i}}$

where, $\mathrm{W}_{\mathrm{i}} \mathrm{s}$ are random variables, defined by the truncation of the normal distribution with zero mean and variance, $\sigma_{u}^{2}$, such that point of truncation by $-\mathrm{Zi} \delta$, i.e., $\mathrm{W}_{\mathrm{i}} \geq \mathrm{Z}_{\mathrm{i}} \delta$.

Besides the farm-specific variables, the Z-variable in Eq. 2 may also include input variables in the stochastic production frontier (1), provided that the inefficiency effects are stochastic. If Z-variables also include interactions between farm-specific and input variables, then the Huang and Liu (1994) non-neutral stochastic frontier is obtained.

The technical efficiency of the ith sample firm, denoted by $\mathrm{TE}_{\mathrm{i}}$, is given as:

$\mathrm{TE}_{\mathrm{i}}-\exp (-\mathrm{U})=\mathrm{Y}_{\mathrm{i}} /\left\{\mathrm{f}\left(\mathrm{X}_{\mathrm{i}} ; \beta\right) \exp \left(\mathrm{V}_{\mathrm{i}}\right)\right\}$

where, $f\left(X_{i} ; \beta\right) \exp \left(V_{i}\right)$ is the stochastic frontier production. The prediction of technical efficiencies is based on the conditional expectation of the expression (3), given by the model specifications (Battese and Colli, 1988).

Parameter V represents the symmetric error term form and $\mathrm{U}$ represents the one-sided error component. In the stochastic production function $\mathrm{f}(\mathrm{X}) \exp (\mathrm{V}), \mathrm{V}$ has a symmetric distribution to capture the random effects of measurement error and exogenous shocks, which cause the placement of the deterministic kernel $\mathrm{f}(\mathrm{X})$ to vary across firms. Technical inefficiency relative to the stochastic production frontier is then captured by the one-sided error component exp (-U), $U \geq 0$. The condition $U \geq 0$ ensures that all observations lie below the stochastic production frontier. Unfortunately, there is no way of determining whether 
the observed performance of a particular observation compared with the deterministic kernel of the frontier is due to inefficiency or to random variation in the frontier. This constitutes the main weakness of the stochastic frontier model. It is not possible to decompose individual residuals into their two components and so it is not possible to estimate technical inefficiency by observation. The best that one can do is to obtain an estimate of mean efficiency over the sample.

Empirical model of stochastic frontier: In order to estimate the level of technical efficiency in a manner consistent with the theory of production function, Cobb-Douglas type stochastic frontier production function was used in the present study.

The Cobb-Douglas form of production function has some well-known properties that justify its wide application in economic literature (Henderson and Quandt, 1980). It is a homogeneous function that provides a scale factor enabling one to measure the return to scale and to interpret the elasticity coefficients with relative ease. It is also easy to estimate and mathematically manipulate. At the same time, the Cobb-Douglas production function makes several restrictive assumptions. It is assumed that the elasticity coefficients are constant, implying constant share for the inputs. The elasticity of substitution among factors is unity in the Cobb-Douglas form. Moreover, this being linear in logarithm, output is zero if any of the inputs is zero and output expansion path is assumed to pass through the origin. However, it is also argued that if interest rests on efficiency measurements and not on an analysis of the general structure of the underlying production technology, the Cobb-Douglas specification provides an adequate representation of the production technology. In addition, its simplicity and widespread use in agricultural economics outweigh its drawbacks. Translog stochastic production function is also used to estimate the significant relation of different variables which in turn affects the level of efficiency. Translog function is a flexible functional form. But it is more difficult to mathematically manipulate and can suffer from degree of freedom and multicollinearity problems (Rahman, 2002). However, large sample size is needed for Translog functional form. Total sample size of the present study was 100 , which may be considered not large enough for Translog functional form.

In consideration of the above fact, Cobb-Douglas type functional form had been tried in this study.

The Cobb-Douglas stochastic production frontier model can be specified as:

$\operatorname{Lny}_{\mathrm{i}}=\beta_{0}+\sum_{\mathrm{i}=1}^{\mathrm{n}} \beta_{\mathrm{i}} \mathrm{x}_{\mathrm{i}}+\varepsilon_{\mathrm{i}}$
All lower case variables are defined in natural logs. The subscripts $i$ refers to the ith observation where $i=1,2$, $3, \ldots \ldots . . . n$ (farms)

$\mathrm{y}_{\mathrm{i}}=$ Production of chili

$\mathrm{x}_{\mathrm{i}}=$ Inputs use in chili cultivation

$\varepsilon_{\mathrm{i}}=\left(\mathrm{v}_{\mathrm{i}}-\mathrm{u}_{\mathrm{i}}\right)=$ A composite error, where $\mathrm{v}_{\mathrm{i}} \sim$ i.i.d. $\mathrm{N}$ $\left(0, \sigma^{2}\right)$ and $/ u_{i} / \sim$ i.i.d. $N\left(\mu, \sigma^{2}\right)$

The technical efficiency $\mathrm{TE}_{\mathrm{i}}=\left(\mathrm{u}_{\mathrm{i}}\right)$ of the ith firm is a non-negative random variable and follows a normal distribution truncated at zero. The mean technical efficiency input is output variable and Xs are input related variables, defined previously and the technical inefficiency effects, $\mu_{\mathrm{i}}$ is given by the efficiency model in Eq. 5:

$\mu_{\mathrm{i}}=\delta_{0}+\sum_{\mathrm{i}=1}^{3} \delta_{\mathrm{i}} \mathrm{z}_{\mathrm{i}}$

The efficiency-effects are proxies by Zs, which are farm specific variables and $\delta_{0}$ is unknown parameters to be estimated.

The parameters for the stochastic production frontier model and those for the technical inefficiency model would be estimated simultaneously using the Maximum Likelihood Estimation (MLE) method by Frontier 4.1 program, which estimates the variance parameters of the likelihood function.

\section{RESULTS}

Sample characteristics: The characteristics of the sample farms are shown in Table 1. Average total own land was 1.27 ha, net cultivated land 1.22 ha and area under chili was 0.13 ha. Cropping patterns followed in chili land was Jute-Chili (100\%). Soil is mainly loamy. Planting started from mid September and continued up to mid November. Harvesting started from January and ended in mid April. Attack of pest and diseases was the main problem for chili cultivation.

Input use: Data presented in Table 2 shows the input use for cultivation of chili in 1 ha of land. Land preparation was done mainly by power tiller and draft animal power. The average power tiller and draft animal power cost was Tk 3523. The average human labor required in 1 ha of land was 333 man-days of which only $8 \%$ was provided from the farmers' own family. Harvesting was done with female and child worker with a lower wage rate. 
Farmers used $28 \mathrm{~kg}$ chili as seed to cultivate 1 ha of land. Farmers used organic manure (cow dung and ash) at the rate of 3.13 tonne $\mathrm{ha}^{-1}$. On average, in $1 \mathrm{ha}$ of land $315 \mathrm{~kg}$ of Urea, $12 \mathrm{~kg}$ of TSP, $75 \mathrm{~kg}$ of MP, $57 \mathrm{~kg}$ of SSP and $158 \mathrm{~kg}$ of DAP were used by the farmers. That means that, on an average they used $173 \mathrm{~kg} \mathrm{ha}^{-1}$ of $\mathrm{N}, 39 \mathrm{~kg} \mathrm{ha}^{-1}$ of $\mathrm{P}, 38 \mathrm{~kg} \mathrm{ha}^{-1}$ of $\mathrm{K}$ and $7 \mathrm{~kg} \mathrm{ha}^{-1}$ of S.

A total of Tk 1,313/- was spent ha ${ }^{-1}$ for controlling disease and pest. The average cost of irrigation was Tk $3,136 /-\mathrm{ha}^{-1}$ for 3 times irrigation.

Cost and return: On an average total variable cost of production and total cost of production per ha of land were Tk 71,950/- and Tk 78,950/-, respectively (Table 3).

Table 1: Summary data on sample characteristics

\begin{tabular}{ll}
\hline Average total own land (ha) & 1.27 \\
Average net cultivated land (ha) & 1.22 \\
Average area under chili (ha) & 0.13 \\
Cropping pattern in chili land & Jute-Chili $100 \%$ \\
Land type & Medium high $1 \%$ \\
& Medium $99 \%$ \\
Soil type & Clay loam $2 \%$ \\
& Loam 98\% \\
Planting & Mid September-Mid November \\
& Ashin-1-Kartik-4 \\
Harvesting & January-Mid April \\
& Poush-2-Baishak-1 \\
No. of cultivation & 4 \\
No. of weeding & 4 \\
No. of irrigation & 3 \\
Problems to cultivate chili & Attack of diseases for low temperature \\
\hline
\end{tabular}

The total yield was $7,052 \mathrm{~kg} \mathrm{ha}^{-1}$ and the gross return was Tk 1,52,114/-. Price of red chili $\left(T k 22 /-\mathrm{kg}^{-1}\right.$ ) was higher than green chili (Tk $\left.17 / \mathrm{kg}^{-1}\right)$. For cultivating chili in 1 ha of land, gross margin obtained was Tk $80,164 /-$ and the net return or profit was Tk 73,164/-. The undiscounted Benefit Cost Ratio (BCR) was 1.93 for chili cultivation.

Maximum-likelihood estimates of the Cobb-Douglas production function: The maximum-likelihood estimates for parameters of the Cobb-Douglas stochastic production frontier model and those in the technical inefficiency model for chili are presented in Table 4. Most of the parameters were statistically significant and one of the parameters were lacking in the expected sign. The sign of the parameters of power tiller and draft power cost is negative and significant at $1 \%$ level.

Table 2: Use of different inputs to cultivate chili ha ${ }^{-1}$ of land

\begin{tabular}{llrrr}
\hline Particulars & Unit & Own & Hired & Total \\
\hline $\begin{array}{l}\text { Power tiller/ } \\
\text { draft power }\end{array}$ & Taka & 1527 & 1996 & 3523 \\
Human labor & man-days & 28 & 305 & 333 \\
Seed & $\mathrm{Kg}$ & 28 & - & 28 \\
Cow dung & $\mathrm{Kg}$ & 3090 & - & 3090 \\
Ash & $\mathrm{Kg}$ & 41 & - & 41 \\
Urea & $\mathrm{Kg}$ & - & 315 & 315 \\
TSP & $\mathrm{Kg}$ & - & 12 & 12 \\
MP & $\mathrm{Kg}$ & - & 75 & 75 \\
Gypsum & $\mathrm{Kg}$ & - & 1 & 1 \\
SSP & $\mathrm{Kg}$ & - & 57 & 57 \\
DAP & $\mathrm{Kg}$ & - & 158 & 158 \\
Insecticide & Taka & - & 1313 & 1313 \\
Irrigation & Taka & - & 3136 & 3136 \\
\hline
\end{tabular}

Table 3: Cost and return for cultivating chili ha ${ }^{-1}$ of land

\begin{tabular}{|c|c|c|c|c|}
\hline Particulars & Unit & Own & Hired & Total \\
\hline Power tiller/draft power & Taka & 1527 & 1996 & 3523.00 \\
\hline Human labor & Taka & 3760 & 41240 & 45000.00 \\
\hline Seed & Taka & 1932 & - & 1932.00 \\
\hline Cow dung & Taka & 773 & - & 773.00 \\
\hline Ash & Taka & 21 & - & 21.00 \\
\hline Urea & Taka & - & 3780 & 3780.00 \\
\hline TSP & Taka & - & 840 & 840.00 \\
\hline MP & Taka & - & 4500 & 4500.00 \\
\hline Gypsum & Taka & - & 8 & 8.00 \\
\hline SSP & Taka & - & 2280 & 2280.00 \\
\hline DAP & Taka & - & 3318 & 3318.00 \\
\hline Insecticide & Taka & - & 1313 & 1313.00 \\
\hline Irrigation & Taka & - & 3136 & 3136.00 \\
\hline Int. on op. capital & Taka & 174 & 1352 & 1526.00 \\
\hline Total variable cost & Taka & & & 71950.00 \\
\hline Rental value of land & Taka & & & 7000.00 \\
\hline Total cost & Taka & & & 78950.00 \\
\hline Gross yield: Green chili & $\mathrm{Kg}$ & & & 606.00 \\
\hline Red chili & $\mathrm{Kg}$ & & & 6446.00 \\
\hline Total chili & $\mathrm{Kg}$ & & & 7052.00 \\
\hline Gross return: Green chili & Taka & & & 10302.00 \\
\hline Red chili & Taka & & & 141812.00 \\
\hline Total chili & Taka & & & 152114.00 \\
\hline Gross margin & Taka & & & 80164.00 \\
\hline Net return & Taka & & & 73164.00 \\
\hline BCR & & & & 1.93 \\
\hline
\end{tabular}


Am. J. Applied Sci., 7 (2): 185-190, 2010

Table 4: Maximum-likelihood estimates for the Cobb-Douglas production function of chili cultivation

\begin{tabular}{|c|c|c|c|c|}
\hline Variable & Parameter & Coefficient & Std.-error & t-ratio \\
\hline \multicolumn{5}{|l|}{ Stochastic frontier } \\
\hline Constant & $\beta_{0}$ & 4.92745 & 1.000570 & 4.92000 \\
\hline Land preparation cost $\left(\mathrm{Tk} \mathrm{ha}^{-1}\right)$ & $\beta_{1}$ & -0.20894 & 0.100830 & -2.07000 \\
\hline Human labor (man-days $\mathrm{ha}^{-1}$ ) & $\beta_{2}$ & 0.28817 & 0.129820 & 2.22000 \\
\hline Seed $\left(\mathrm{kg} \cdot \mathrm{ha}^{-1}\right)$ & $\beta_{3}$ & 0.29840 & 0.166220 & 1.80000 \\
\hline Organic manure $\left(\mathrm{kg} \mathrm{ha}^{-1}\right)$ & $\beta_{4}$ & 0.00064 & 0.002010 & 0.32000 \\
\hline Fertilizer $\left(\mathrm{kg} \mathrm{ha}^{-1}\right)$ & $\beta_{5}$ & 0.15629 & 0.098720 & 1.58000 \\
\hline Insecticide $\left(\mathrm{Tk} \mathrm{ha}^{-1}\right)$ & $\beta_{6}$ & 0.00438 & 0.003490 & 1.26000 \\
\hline Irrigation $\left(\mathrm{Tk} \mathrm{ha}^{-1}\right)$ & $\beta_{7}$ & 0.27703 & 0.088920 & 3.11000 \\
\hline \multicolumn{5}{|l|}{ Inefficiency model } \\
\hline Constant & $\delta_{0}$ & 0.56821 & 0.653840 & 0.86905 \\
\hline Age (years) & $\delta_{1}$ & -0.08551 & 0.042690 & -2.00000 \\
\hline Education (year of schooling) & $\delta_{2}$ & -0.31872 & 0.168330 & -1.89000 \\
\hline Area under chili (decimal) & $\delta_{3}$ & 0.01398 & 0.008580 & 1.63000 \\
\hline \multicolumn{5}{|l|}{ Variance parameters } \\
\hline Sigma-Sq. & $\sigma^{2}$ & 1.24794 & 0.511850 & 2.43000 \\
\hline Gamma & $\gamma$ & 0.98446 & 0.006479 & 151.94000 \\
\hline Log-likelihood & & -18.44000 & & \\
\hline LR test of the one-sided error & & 59.57000 & & \\
\hline Mean efficiency & $\mu_{\mathrm{i}}$ & 0.77000 & & \\
\hline
\end{tabular}

Table 5: Frequency distribution of farm-specific technical efficiency estimates from Cobb-Douglas stochastic frontiers for chili production

\begin{tabular}{lc}
\hline Efficiency level & Frequency \\
\hline $11-15$ & 2.00 \\
$16-20$ & - \\
$21-25$ & 1.00 \\
$26-30$ & 1.00 \\
$31-35$ & 1.00 \\
$36-40$ & 1.00 \\
$41-45$ & 2.00 \\
$46-50$ & 1.00 \\
$51-55$ & 1.00 \\
$56-60$ & 4.00 \\
$61-65$ & 2.00 \\
$66-70$ & 7.00 \\
$71-75$ & 11.00 \\
$76-80$ & 11.00 \\
$81-85$ & 12.00 \\
$86-90$ & 26.00 \\
$91-95$ & 16.00 \\
$96-100$ & 1.00 \\
Total number of farms & 100.00 \\
Mean efficiency $\left(\mu_{\mathrm{i}}\right)$ & 0.77 \\
Minimum efficiency & 0.11 \\
Maximum efficiency & 0.96 \\
\hline
\end{tabular}

The coefficients associated with human labor and irrigation costs were found to be highly significant and coefficient of seed was found significant. Coefficient of fertilizer and pesticide cost was positive, but its' impact was not significant. In this study, output elasticity of inputs was the highest for seed, followed by human labor and irrigation cost, but they were almost same $0.29,0.28$ and 0.27 respectively.

The estimated $\delta$-coefficient in Table 4 associated with the explanatory variables in the model for the inefficiency effects are worthy of particular discussion.
It was observed that education and age of the farmers had a significantly negative effect upon the inefficiency effects for chili production which was expected.

The sign of the coefficients of area under chill is positive and significant. Models were well fitted to the data; sigma sq. was statistically highly significant. Random effect, which was out of control of farmers, had significant effect in chili production. The highly significant value of gamma showed that there were technical inefficiency effects in chili production in the study area. This means that about $98 \%$ of the differences between the observed output and maximum production frontier output were caused by differences in farmers' levels of technical efficiency. The value of general Likelihood Ratio (LR) test was 59.57 and the critical value of this test was $\chi_{0.05(40)}^{2}=55.19$ (Kodde and Palm, 1986).

The farm specific technical efficiency coefficients for chili derived from the above stochastic frontier varied from $11-96 \%$ and their mean technical efficiency was $77 \%$ (Table 5 ).

\section{DISCUSSION}

Farmer's use of Urea was much higher than the recommended dose. To cultivate chili in 1 ha of land the recommended doses of fertilizers were $31-60 \mathrm{~kg} \mathrm{~N}$, 21-40 kg P, 31-60 kg K and 6-10 kg S in medium quality soil. In low quality soil, recommended doses were 61-90 kg N, 41-60 kg P, 61-90 kg K and 11-15 kg S (Bangladesh Agricultural Research Council, 2005).

The negative and significant sign of the parameters of power tiller and draft power cost for land preparation 
means that the rate of output decreases with the increase of these inputs. The reason for negative coefficients can be explained by their inappropriate use. Human labor, seed and irrigation were found to act as important factors and had positive impact on chili production. Sum of the quantity of Urea, TSP, MP, SSP and DAP was taken as the variable fertilizer. By taking Urea, TSP, MP, SSP and DAP as individual variables, multicollinearity problem arose among these variables. Non-significant parameters of fertilizer and pesticide cost means that fertilizer and pesticide cost had no effect on technical efficiency.

The higher levels of formal education of the farmers tend to have smaller inefficiencies than the lower levels of formal education of the farmers which means that the inefficiency effect in production decrease with the increase in formal education of the farmers. In other words, the farmers with higher level of education are technically more efficient than those with lower level of education. Aged farmers are experienced and they are efficient. That means larger area under chili per farm is not efficient.

The significant value of LR test also reveals that there was technical inefficiency effect in the production of chili.

\section{CONCLUSION}

It is apparent from the above discussion that cultivation of chili was highly profitable in Jamalpur district. Although, a huge amount of cash was needed for cultivation of this crop, farmers could obtain higher amount of profit. Seed, human labor and irrigation cost were identified as important factors for the increase of chili production. Present study reveals that for chili all of the farmers were found to have produced outputs which were not very close to the maximum frontier outputs (efficiency levels varying from 11-96\% and their mean efficiency was $77 \%$ ). On average, $23 \%$ technical inefficiencies appears, which implies that the output per farm could be increased on average by $23 \%$ for chili production under the prevailing technology without incurring any additional production costs. Side by side advanced technology (high yielding variety, disease and pest management) could be adapted to increase production of this spice. It tends to suggest that the research for the development of improved varieties of chili should be undertaken in the long run.

The models for the technical inefficiency effects in the stochastic production frontiers included age, education and farm size. Technical efficiency increase as farmers' formal education increases. Education should be one of the top priorities to develop the necessary human capital for sustainable development. Younger farmers need to train up to increase their efficiency.

\section{REFERENCES}

Bangladesh Agricultural Research Council, (BARC), 2005. Fertilizer Recommendation Guide. BARC.

Battese, G.E. and T.J. Colli, 1988. Prediction of firmlevel technical efficiencies with a generalized frontier production function for panel data. J. Econ., 38: 387-399. DOI: 10.1016/03044076(88)90053-X

Battese, G.E. and T.J. Colli, 1995. A model for technical efficiency effects in a stochastic frontier production function of panel data. Empiric. Econ., 20: 325-332. DOI: 10.1007/BF01205442

Henderson, J.M. and R. Quandt, 1980. Microeconomic Theory: A Mathematical Approach. 3rd Edn., McGraw-Hill, ISBN: 13:9780070280894, pp: 420.

Huang, C.J. and J.T. Liu, 1994. Estimation of a nonneutral stochastic frontier production function. J. Prod. Anal., 5: 171-180. DOI: 10.1007/BF01073853

Karvy, 2008. Seasonal outlook on chili. Karvy Special Reports, Karvy Comtrade. Limited. http://www.karvycomtrade.com/downloads/karvyS pecialReports/karvysSpecialReports_20080908_01 .pdf

Kodde, D.A. and F.C. Palm, 1986. Wald Criteria for jointly testing equality and inequality restrictions. Econometrica, 54: 1246. http://www.jstor.org/stable/1912331

Rahman, K.M.M., 2002. Measuring Efficiency of Producing Rice in Bangladesh: A Stochastic Frontier Analysis. Wiss.-verl. Vauk, Kiel, ISBN: 38175-0357-1, pp: 215.

Zellner, A., J. Kemnta and J. Dreze, 1966. Specification and estimation of Cobb-Douglas production function models. Econometrica, 34: 784-795. http://www.jstor.org/stable/1910099 